\section{Development of a pressure-measuring device to optimize compression treatment of lymphedema and evaluation of change in garment pressure with simulated wear and tear}

\section{Håkan Brorson, Emma Hansson, Erik Jense, Carolin Freccero \\ Department of Clinical Sciences, Lund University, Plastic and Reconstructive Surgery, Skåne University Hospital, Malmö, Sweden}

\section{Introduction}

A variety of pressure transducers have been used in studies to measure surface pressures at the interface between compression garments and the skin; for example, the Kikuhime device ${ }^{3}$ (TT Medi Trade, Sorø, Denmark) and the I-scan system ${ }^{1-4}$ (Tekscan Inc., Boston, MA). The I-scan system uses one or multiple sensors and is ultra thin $(0.15$ $\mathrm{mm}$ ). In most of the studies, subgarment or subbandage pressure has been measured merely at one or a few levels along the extremity. In 1997, Mann et al. measured in vivo mean subgarment pressure under burn garments using the I-scan system with sensor 9801 and found a high validity and reliability $(\mathrm{r}=1) .{ }^{1,2}$ Liu et al. (2005) measured in vivo subgarment pressure, on garments used for venous disorders, using Tekscan FlexiForce interface pressure sensors along the leg at 4 different levels. ${ }^{3}$ Macintyre (2007) measured in vivo subgarment pressure under burn garments along the extremity in order to optimize compression using the I-scan system with sensor 9801.4

The aims of this study were to establish a method of measuring subgarment pressure using the I-scan (Tekscan Inc.) pressure measuring equipment, and to analyze initial and post-wear and tear subgarment pressure along the extremity of 5 similar compression garments from three different manufacturers.

\section{Materials and Methods}

\section{Plastic legs and garments}

Fifteen identical plastic lower legs, made of recyclable high-density polyethylene with a hard surface were used. Measurements for ordering of garments were taken according to standard procedures on one of the legs. Five custom-fitted and flat-knitted below the knee compression garments, compression class 3 , compression range: $34.0-46.0 \mathrm{mmHg}$, were ordered from each of the 3 different manufacturers. The manufacturers were not informed that the garments were intended for a study.

\section{Pressure measuring device and cali- bration}

All pressure measurements were made with I-scan system (Tekscan Inc.) with an ultra-thin flexible sensor $(0.15 \mathrm{~mm})$, sensor model 9801. The sensor was split in half and trimmed down leaving 24 sensor points for the analyses. Measurements were directly recorded on a PC via a transducer (Tekscan, Model EH-2). The Tekscan software presents the measurements both in a numerical and a graphical way. All the readings were exported to Excel. The sensor and the software were calibrated with a linear calibration tool (Tekscan, Model PB5A).

\section{Measurements}

To achieve a texture that resembles the softness of human tissue, measurements were performed on three different configurations: i) bare legs; ii) legs lined with standard Velcro made of $100 \%$ Polyamide (Velcro); and iii) legs lined with foam material (Poron urethane foam) A total of 24 measuring points were used. All graphs show the distance $(\mathrm{cm})$ along the lower leg on the $\mathrm{x}$-axis, were distance 0 $\mathrm{cm}$ equals the malleolus. The y-axis represents the force (mmHg) applied by the compression garment in each given point along the lower leg.

\section{Initial measurements and simulation of wear and tear}

The initial measurements were made on the garments fresh from the manufacturers. To be able to assess the decline in subgarment pressure over time, wear and tear of the garments was simulated by washing in the evening, drying overnight, and then put on to the plastic legs during the next day. This procedure was repeated for 7 days between each measurement, which was made in the evening of the seventh day. The procedure was repeated for 4 weeks. The garments were washed in a washing machine according to a standard careful washing program at $40^{\circ} \mathrm{C}$.

\section{Statistical methods}

The measured factors were not statistically normally distributed and hence values are presented as medians and range or $1 \mathrm{q}-3 \mathrm{q}$, and nonparametric methods were consistently used. The initial pressure in each of the 24 pressure points was calculated from the mean exerted pressure of 5 garments from each manufacturer. The mean of all 24 pressure points along the garment was used to calcu-
Correspondence: Håkan Brorson, Department of Clinical Sciences, Lund University, Plastic and Reconstructive Surgery, Skåne University Hospital, Malmö, Sweden.

E-mail: hakan.brorson@med.lu.se

Conference presentation: International Compression Club (ICC) Meeting, Rotterdam, 2018.

Notes: this extended abstract is published with permission from Lymphat Res Biol and is a condensation of a previously published paper: Brorson H, Hansson E, Jense E, Freccero C. Development of a pressure-measuring device to optimize compression treatment of lymphedema and evaluation of change in garment pressure with simulated wear and tear. Lymphat Res Biol 2012; 10: 74-80.

This work is licensed under a Creative Commons Attribution 4.0 License (by-nc 4.0).

(C) Copyright H. Brorson et al., 2018

Licensee PAGEPress, Italy

Veins and Lymphatics 2018; 7:7986

doi:10.4081/vl.2018.7986

late the pressure gradient of each garment Differences over time within the groups were analyzed using the Wilcoxon signed rank test, and differences between groups were analyzed with the Mann-Whitney test. The outcome of the significance tests was considered as exploratory results; therefore nominal $\mathrm{P}$ values are presented without any adjustment for multiple comparisons. A P value of 0.05 or less was considered to indicate a statistically significant difference.

\section{Results}

The evaluation of the three materials to measure on revealed that the foam material had a tonometry value of $30 \mathrm{~N} / \mathrm{mm}^{2}$, which is close to that of a normal human leg. ${ }^{5}$

Figure 1 shows the initial median pressure outcome of all measurements along the leg of each set of compression garment. There was a statistically significant difference in initial exerted subgarment pressure between the garment of Company 1 and 2 $(\mathrm{P}=0.009)$ and between Company 1 and 3 $(\mathrm{P}=0.028)$, but not between Company 2 and 3 $(\mathrm{P}=0.531)$ (Table 1).

During the wear and tear period there were significant differences between the manufacturers (Table 1).

There was no significant decrease in subgarment pressure from any manufacturer during the observation period (Figure 2). 


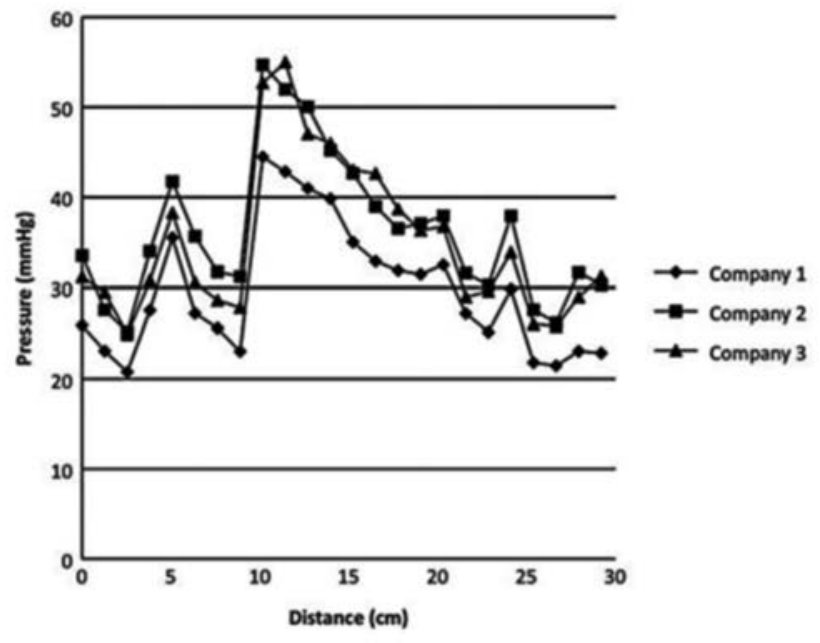

Figure 1. Initial median pressure gradient along the leg of all 5 garments from the 3 manufacturers. For statistical outcome.

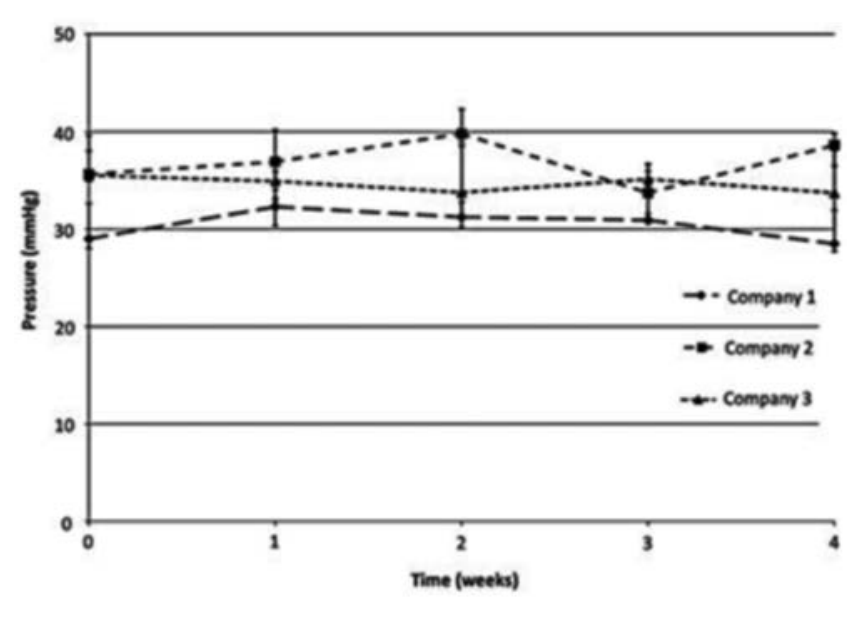

Figure 2. Median (1q and 3q) subgarment pressures from all 24 measuring points of 5 garments during 4 weeks' of washing. For statistical outcome, see Table 1.

Table 1. Comparison between groups before (fresh) and during 4 weeks' of wear and tear.

\begin{tabular}{lccc} 
& Company 1 ws 2 & Company 1 ws 3 & Company 2 os 3 \\
Fresh & $\mathrm{P}<0.009^{*}$ & $\mathrm{P}<0.028^{*}$ & $\mathrm{P}<0.531$ \\
1 week & $\mathrm{P}<0.009^{*}$ & $\mathrm{P}<0.117$ & $\mathrm{P}<0.175$ \\
\hline 2 weeks & $\mathrm{P}<0.009^{*}$ & $\mathrm{P}<0.602$ & $\mathrm{P}<0.009 *$ \\
3 weeks & $\mathrm{P}<0.256$ & $\mathrm{P}<0.117$ & $\mathrm{P}<0.465$ \\
\hline 4 weeks & $\mathrm{P}<0.009^{*}$ & $\mathrm{P}<0.022^{*}$ & $\mathrm{P}<0.037 *$ \\
\hline *P $<0.05$ & & &
\end{tabular}

\section{Conclusions}

Previous research has showed that the subgarment pressure used often is higher than needed for sufficient treatment. ${ }^{6}$

Little is known about the longevity of garments and the optimal pressure required for adequate treatment. ${ }^{7}$ This study set out to establish a method for measuring the actual subgarment pressure provided, during wear and tear, by using the Tekscan pressure-measuring equipment. The lack of significant difference within each manufacturer's garments as compared to initial values, during the 4 weeks of wear and tear, may indicate high quality and maintenance of pressure in the compression garments during the first weeks of usage. However, to truly evaluate the effect of wear and tear, and decrease in subgarment pressure, a longer study period of at least 3-6 months, corresponding to garments' normal life span according to the manufacturers, would be needed.

This study shows that all garments did not show a continuous drop in pressure from distal to proximal leg. We have no clear explanation of the sudden increase at the 10 $\mathrm{cm}$ level. The same outcome was found when
Velcro and no padding were used, and when different parts of the sensor were tested. It could be due to increase in leg diameter at this point, but this should be compensated for by the manufacturer according to measurements of the patient's leg. In conclusion, there was an initial difference between some of the manufacturers' garments. However, the homogeneity within garments from the same manufacturer was satisfying. No significant decrease of subgarment pressure was observed during the trial period. The study demonstrated that Tekscan pressure-measuring equipment could be used to measure subgarment pressure in vitro. Nonetheless, it would be of interest to develop a modified simpler sensor for a more straight forward subgarment pressure measurements to be able to perform in vivo measurements in a time efficient way and to promote further research in the field.

\section{References}

1. Mann R, Yeong EK, Moore ML, Engrav LH. A new tool to measure pressure under burn garments. J Burn Care
Rehabil 1997;18:160-3; discussion 159.

2. Mann R, Yeong EK, Moore M, et al. Do custom-fitted pressure garments provide adequate pressure? J Burn Care Rehabil 1997;18:247-9.

3. Liu R, Kwok YL, Li Y, et al. Objective evaluation of skin pressure distribution of graduated elastic compression stockings. Dermatol Surg 2005;31:615-24.

4. Macintyre L. Designing pressure garments capable of exerting specific pressures on limbs. Burns 2007;33:579-86.

5. Bagheri S, Ohlin K, Olsson G, Brorson H. Tissue tonometry before and after liposuction of arm lymphedema following breast cancer. Lymphat Res Biol 2005;3:66-80.

6. Damstra RJ, Partsch H. Compression therapy in breast cancer-related lymphedema: a randomized, controlled comparative study of relation between volume and interface pressure changes. J Vasc Surg 2009;49:1256-63.

7. Partsch H, Flour M, Smith PC. Indications for compression therapy in venous and lymphatic disease consensus based on experimental data and scientific evidence. Under the auspices of the IUP. Int Angiol 2008;27:193-219. 